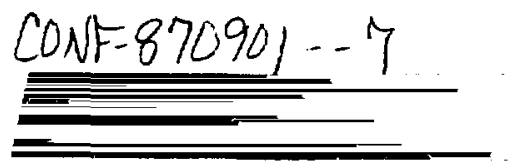

DISCLAIMER
Preprint

UCRL- -96288

DEB8 000972

This repon was prepared as an account of work sponsored by an agency of the United States Government. Neither the United States Government nor any agency thereol, nor any of their employees, makes any warranty, express or implied, or assumes any legal liability or responsibility for the accuracy, completeness, or usefulness of any information, apparatus, product, or process disclosed, or represents that its use would not infringe privarely owned rights. Reference berein to any specific commercial product, process, or service by trade nam-, tredemark, manufactures, or otherwise does not necessatily constitute or imply its endarsement, recommendation, or favoring by the United States Government or any agency theroof. The views and opinions of authors expresed herein do not necessarily stute or reflect those of the United States Government or any agency thereof.

\title{
Development of a Laced Electromagnetic Wiggler
}
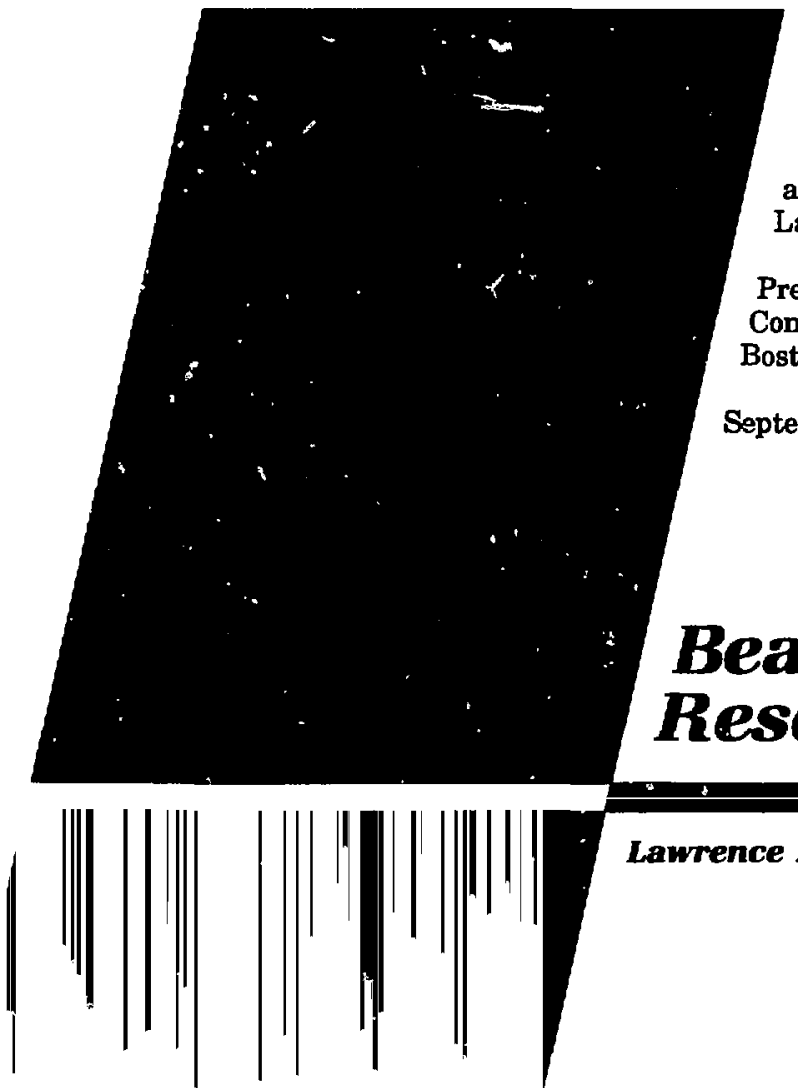

T. C. Christensen, M. J. Burns, G. A. Deis, C. V. Parkison, and D. Prosnitz Lawrence Livert ore National Laboratery

and $\mathbf{K}$. Halbach

Lawrence Berkeley saboratory

Prepared for the Tenth International Conference on Magnet Technology Boston, Massachusetts

September 23-26, 1987

₹

\section{Beam} Research Program

\section{Lawrence Livermore National Laboratory}

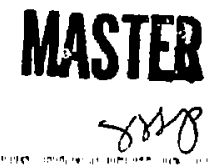


DISCI.AIMIE.

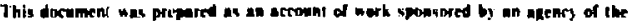

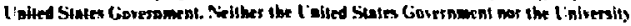
of Californin wor any of their employees ankes any warraty, en press or impliet, or assemes any lezal linbility of responsibility for the accuracy, completemess, or useful. ness of any information. apmaratme modurt. of provens discloned, or represents that its use noukt not infringe privalely owned rights. Reference herein to any specifie commercisl products, process, ar scrvine by trade name, indemerk, manulart wrer, of otherw ise, does not necessarily constitute ar imply its ed-rsement, recommendation. os favoring by the Inited Sitates Government or the University of Californin. The siens and opinions of authors expreserd herein do not mecessarily state of reflect Ihose of the United States Government or the U'aiversily of Californita and stall not be used for advertising or product emdorsemunt perposes. 


\title{
DEVELOPMENT OF A LACED ELECTROMAGNETIC WIGGLER
}

\author{
T.C. Christensen, M.J. Burns, G.A. Deis, C.D. Parkison, and D. Prosnitz \\ Lawrence Livermore National Laboratory, University of California \\ P.O. Box 808, L-629, Livermore, CA 94550 \\ and \\ K. Halbach \\ Lawrence Berkeley Laboratory \\ One Cyclotron Road, Berkeley, CA 94720
}

\begin{abstract}
The laced electromagnetic wiggler is a new concept being developed to attain higher magnetic fields, shorter wavelengths, and larger gaps for the induction-linear accelerator, free-electron-laser (FEL) program. In the laced wiggler design, permanent magnets are located ("laced") between the uluctromagnetic coils to increase the reversebias flux in the tron pole beyond that possible with only pole-edge ("side") permanent magnets.

This increase in reverse-bias flux allows wiggler operation at midplane magnetic field intensities comparable to those of a hybrid permanent magnet/steel wiggler, but with field adjustability over a specified range. The maximum field intensity and tuning range are selected, within limits, for specific design requirements. We have designed and tested a one-period prototype of this concept with promising results.
\end{abstract}

\section{Introduction}

The laced electromagnetic wiggler uses an ironyoke/pole substructure, water-cooled electromagnetic coils, fine-wire steering coils, and rare-earth/transitionmetal permanent magnets, as shown in Fig. 1.

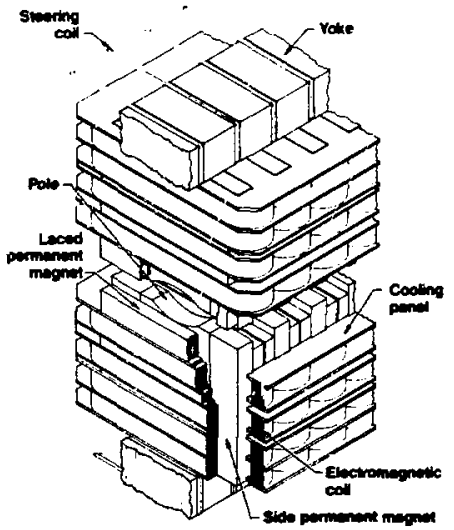

Fig. 1. Laced electromagnelic wiggier.

Our prototype wiggler is designed for a peak magnetic flux density of $5.5 \mathrm{kG}$ at the midplane of a $3-\mathrm{cm}$ gap and has an $8-\mathrm{cm}$ period. The fieid is adjustable over a range of about 1 kG.

We have optimized the laced wiggler pole design and permanent magnet geometry using a modeling code devel- oped at LLNL. This code allows us to investigate the effects of pole geometry, permaneut magnet shape and location, coil current-density, and several other parameters that affect wiggler perfurmance. Our design efforts have centered on maximizing the tuning range and minimizing the powver consumption.

\section{Modeling Wiggler Performance}

The basic physical geometry and midplane magnetic flux density for the laced wiggler are fixed by the physics requirements of the FEL program at LLNL. We analyzed this baseline configuration using the two-ritmensional, magnetustatics code, POISSON, to determine the pole scalar putential needed to obtain the required flux density in the gap, and the resulting magnetic flux in the pole iron. These two parameters are used as input to the LLNL-developed, laced wiggler pole design program, which is used to model wiggler performance.

We have limited the area-averaged flux density to $14 \mathrm{kG}$ in the laced wiggler pole iron to ensure a linear relationship between electromagnet coil current and midplane flux density throughout the tuning range. With this limitation, the losses in the iron are less than about $1 \%$ of the total excitation, and the midplane field is relatively insensilive to material irregularities of a few percent.

The laced wiggler pole design program allows tis to balance the two flux components in the pole iron: (1) the flux from the electromagnet coils and (2) the reverse-bias flux from the permanent magnets. The program determines the size and location of the laced magnets when design parameters for permantent magnet remanance, number of coils, maximum coil rurrent-density, side magnet size, and pole geometry are specified. Figure 2 shows a pole flux-balance plot generated by the pole design program for a baseline laced wiggler design.

Our modeling studies show that pole taper and coil current-density are important factors in determining the tuning range for a laced wiggler. The number of electromagnet crils on the pole, pole-tip curvature, and side permarent magnet thickness are other variables that show a large intluence on the magnetic design. We have investigated several combinations of these variable parameters to determine the optimum laced wiggler configuration for our application. Figure 3 shows the effect of pole taper angle and coil current-density on tuning range for two and four electromagnet coils per pole and a flat pole tip.

Figure 4 shows the effect of side permanent magnet thickness on tuning range for a current density of 1000 $A / \mathrm{cm}^{2}$ and a curved pole tip with 2,3 , and 4 coils per pole.

The maximum current density for an electromagnet coil is limited by the allowable conductor temperature rise 


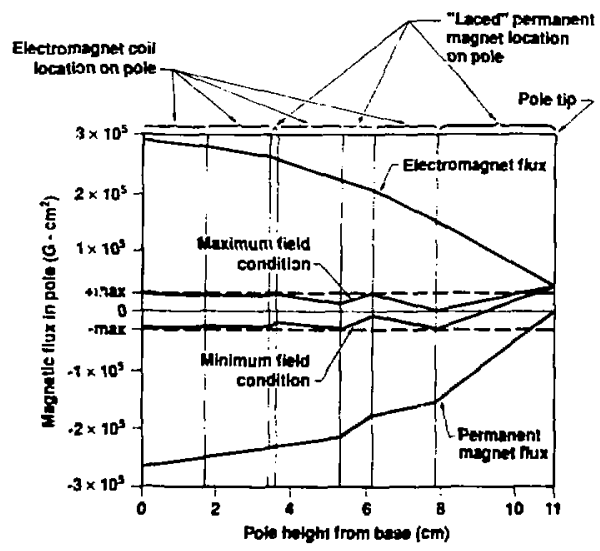

Fig. 2. Pole flux-balance plot for a baseline laced wiggler design.
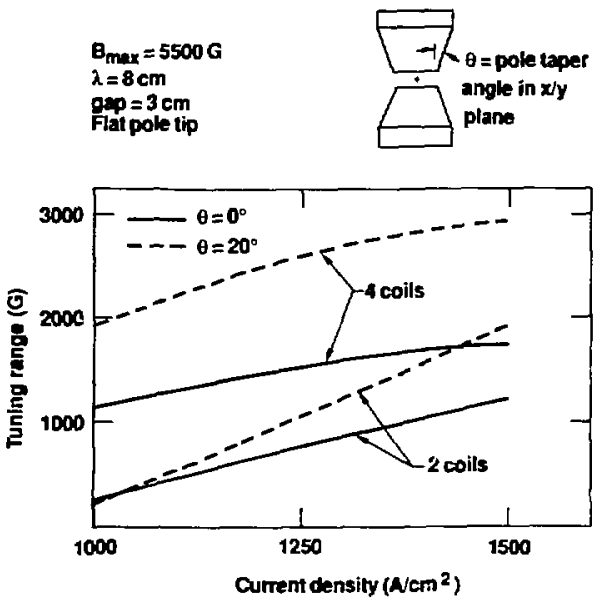

Fig. 3. Pole taper angle and coil current-density effects on laced wiggler tuning range.

caused by resistive heating. At high current densities, conductors can reach temperatures that damage the windingto-winding insulation within the coil assembly. Also, permanent magnets must be shielded from high temperatures to prevent degradation of their magnetic properties.

For an edge-cooled strip magnet using liquid coolant heat-exchanger panels, the current-density can be described by the following equation:

$$
j_{\max }=\frac{1}{2 D_{2}} \cdot \frac{N I}{k_{h}+\frac{k_{c} k_{i}(N I)^{2} \rho}{4 \eta D_{2}^{2} k_{c} \Delta T-(N I)^{2} \rho}},
$$
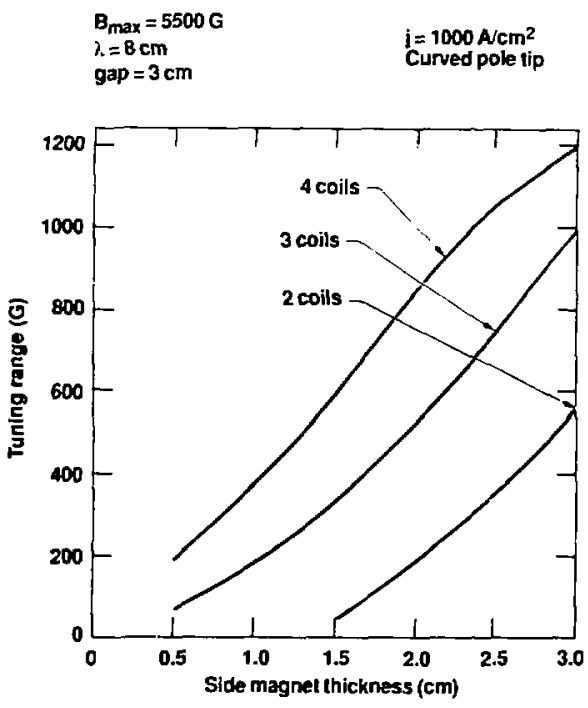

Fig. 4. Side permanent magnet thickness effect on laced wiggler tuning range for a current density of 1000 $\mathrm{A} / \mathrm{cm}^{2}$.

where:

$\mathrm{i}_{\max }=$ maximum current density $\left(\mathrm{A} / \mathrm{cm}^{2}\right)$

$\mathrm{Nl}$ = ampere-turns of electromagnet coil (A-tum)

$\mathrm{D}_{2}=$ width of coil cross section $(\mathrm{cm})$

$t_{\mathrm{b}}=$ heat-exchanger panel thickness $(\mathrm{cm})$

$k_{\mathrm{r}}=$ thermal conductivity of conductor $(\mathrm{W} / \mathrm{cm}-0 \mathrm{C})$

$\mathrm{k}_{\mathrm{i}}=$ coil-to-panel interface conductivity $\left({ }^{\circ} \mathrm{C} / W / \mathrm{cm}^{2}\right)$

$\rho$ = resistivity of conductor $(\Omega-\mathrm{cm})$

$\eta$ = packing fraction of coil (\%)

$\Delta T=$ maximum allowable temperature gradient from coil center to heat-exchanger panel $\left({ }^{\circ} \mathrm{C}\right)$

For a given wiggler geometry and midplane flux density, using electromagnet coils manufactured with highquality materials and proven techniques, only an increase in the allowable temperature gradient $(\Delta T)$ and/or a decrease in the heat-exchanger panel thickness $\left(t_{h}\right)$ offer an appreciable improvement in the maximum coil currentdensity. With our current electromagnet design, the aljowable temperature gradient is limited to approximately $70^{\circ} \mathrm{C}$ when using a $20^{\circ} \mathrm{C}$ coolant supply temperature. With this constraint, an increase in cirrent-density can be made only by decreasing the thickness of the heat-exchanger panel. Figure 5 shows the effect of heat-exchanger panel thickness on coil current-density over a range of scalar potential using four coils per pole.

\section{Laced Wiggler Component Design}

The iaced wiggler yoke/pole assemtly is made from C1008, nonresulfurized carbon steel. We selected this ma- 


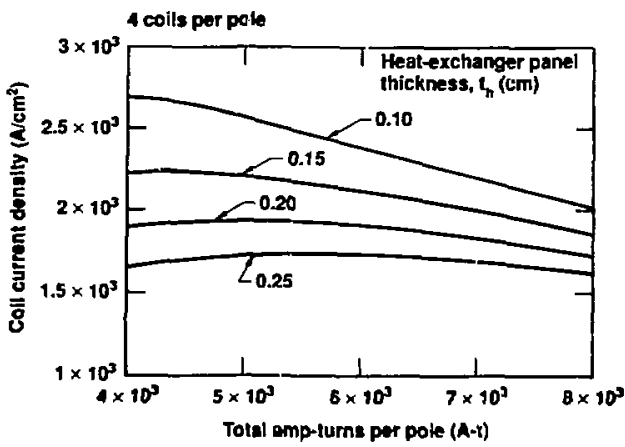

Fig. 3. Effect of heal-exchanger panel thickness on maximum coil current-density.

terial because it is a low-carbon alloy and exhibits greater magnetic permeability than high-carbon steel. The yoke, pole, and pole tip are rough machined from a casting and then precision ground to final dimensions. The completed assembly is then nickel plated for corrosion resistance.

Samarium-cobalt permanent nuagnets are used in the laced wiggler because of their high coercive force $(\geq 8.5$ kOe at $25^{\circ} \mathrm{C}$ ) and resistance to radiation damage. These magnets are prepared with a inaterial composition of rareearth/transition-metal in the ratio: $\operatorname{Re}_{2} \operatorname{Tm}_{17}$.

We fabricate electromagnet coils for the laced wiggler using electrolytic tough-pitch (ETP) copper strip with Nomex ${ }^{R}$ interturn insulation. Individual coils are cut from mandrel-wound, vacuum epoxy-impregnated "logs" and machined to final thickness. We then chemically etch the machined faces of the coils to recess the copper conductor below the edge of the interturn insulation and remove any machining burrs. To complete the assembly, we make a series of electrical checks to confirm proper operation, and apply a spray coating of heat-curing, thermally conductive epoxy to electrically insulate and seal the outer surfaces.

We make cooling panels for the coil assemblies using a chemical-etch /electro-deposition technology developed at LLNL. The coolant flow channels are etched into an oxygen-free, high-conductivity (OFHC) copper substrate using scaled artwork and photoresist methods. The etched channels in the substrate are then filled with wax, surface finished, and coated with silver to make them electrically conductive. The surface of the coated substrate panel is then electroplated with copper to form a layer over the wax-filled channels. We remove the wax by heating the panel and pressure-flushing it with a hot solvent. The panel is completed by machining it to final dimensions and soldering coolant connections in place.

The laced wiggler uses two heat-exchanger panels per electromagnet to provide both coil cooling and high-temperature isolation for the laced permanent magnets. Our current design uses $1.5-\mathrm{mm}$-thick cooling panels bonded directly to the coils with thermally conductive adhesive. This modular design provides improved mechanical protection for the coil faces and the cooling panel and reduces the number of individual components in the wiggler as- sembly. Figure 6 illustrates details of the electromagnet/heat-exchanger panel assembly.

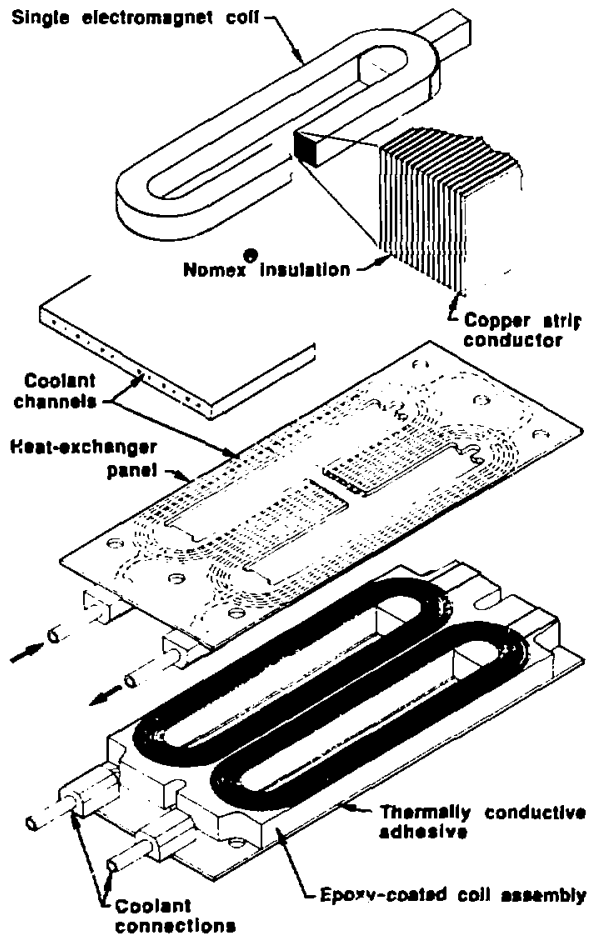

Fig. 6. Details of electromagnet coil/ heat-exchanger panel assembly.

\section{Prototype Laced Wiggler Performance}

We have measured and analyzed the performance of a one-period laced wiggler prototype using a baseline design configuration from our modeling studies. The test results show good agreement with our analytical predictions and confirm the ability of the laced wiggler to attain the desired midplane magnetic flux density and tuning range. Both the nominal wiggle field along the wiggler axis and the focusing field variation are within the acceptable limits of our design requirements. Our modular electromagnet coil/heat-exchanger panel assemblies perform well at their design current-density of $1000 \mathrm{~A} / \mathrm{cm}^{2}$, and temperature measurements indicate that the coils can be operated at substantially greater values without damage.

Our laced wiggler prototype achieved the design midplane flux density of $5.5 \mathrm{kG}$ using $7680 \mathrm{~A}-\mathrm{t}$ per pole. A linear tuning range of approxomately $1.2 \mathrm{kG}$ was obtained between the limits of 4 and $5.2 \mathrm{kG}$. Power consumption at the maximum operating point was about $0.76 \mathrm{~kW}$ per pole. Figure 7 shows the magnetization curve for our protolype.

High-efficiency energy conversion within the wiggler requires a field variation ("taper") along the wiggler axis, 


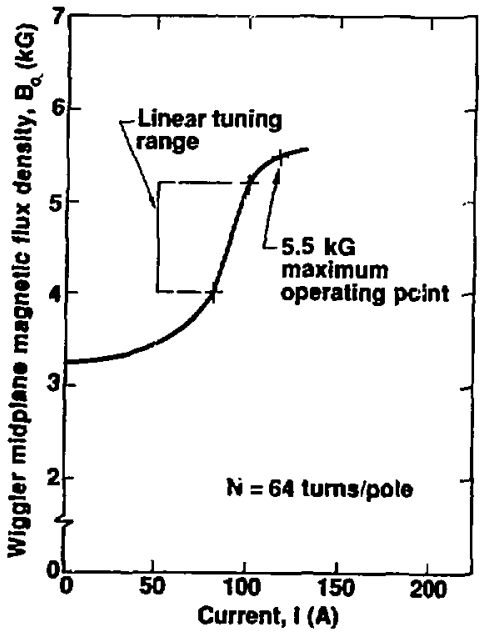

Fig 7 . Magnetization curve for a laced wiggler prototype.

with less than $1 \%$ spatial-harmonir content. A Fourier analysis of the nominal, center-axis, field for the laced wiggler shows a high-quality, sinusoidaily varying fundamental component with low harmonic content. Figure 8 shows the wiggle field variation with axial location for our one-period prototype.

\section{Harmonic Content}

\begin{tabular}{lccc} 
& Amplitude (G) & $\%$ of Fundamental \\
\cline { 2 - 3 } First & 5500 & & 0.34 \\
Third & 18.8 & & 0.32 \\
Fifth & 17.8 & & 0.23 \\
Seventh & 12.9 & & 0.9
\end{tabular}

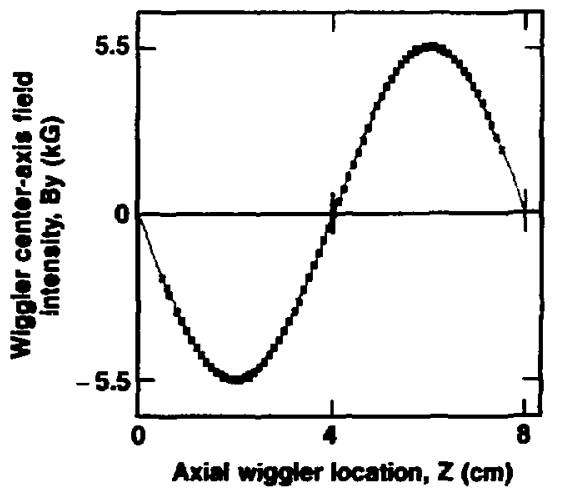

Fig. 8. Wisgle field variation with axial location.
We require a variation in field intensity $\left(B_{y}\right)$ with transverse displacement from the wiggler center axis to provide electron-beam focusing in the wiggle plane. Figure 9 shows the normalized focusing field variation with lateral displacement for the laced wiggler prototype.

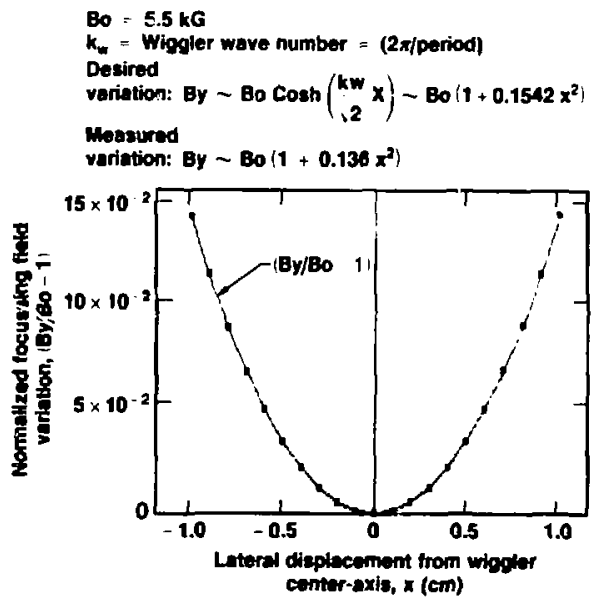

Fig 9. Focusing field variation with latera! displacement from wiggler center axis.

\section{Summary}

The laced electromagnetic wiggler concept has proven successful in meeting the performance requirements for its application in the FEL program at LLNL. We are now focusing $\bar{s}$ us research efforts on advanced electromagnet coil design schelises and methods to reduce the volume of permanent magnet material in the basic wiggler design. Our long-term goal is to devise a iarge-scale, technically feasible, and economically attractive FEL using the laced wiggler design.

Work performed jointly under the auspices of the U.S. Department of Energy by the Lawrence Ijvernore National Laboratory under W-7405-ENG-48 and for the Department of Defense under SDIO/USA-SDC MIPR No. W31RPD-7-D4041. 